\title{
The Impact of Verifiability on Contracts
}

\author{
Dhananjay (Dan) K. Gode \\ Stern School of Business \\ New York University \\ New York, NY 10012
}

Ph: 212-998-0021

Fax: 212-995-4004

E-mail: dgode@stern.nyu.edu

Rajdeep Singh

Carlson School of Management

University of Minnesota

Minneapolis, MN 55455

Ph: 612-624-1061

Fax: 612-626-1335

March 21, 2000

We acknowledge the helpful comments of Sugato Bhattacharyya, Arnold Juster, Arijit Mukherji, Stefan Reichelstein (the editor), Shyam Sunder, two anonymous referees, and seminar participants at Carnegie Mellon University. We are grateful for financial support from the William Larimer Mellon Fund and the Margaret and Richard M. Cyert Family Fund. The first author also acknowledges the financial support of the Deloitte and Touche Foundation. 


\begin{abstract}
We analyze the impact of verifiability on how signals about agents are used to mitigate adverse selection. We show that if signals are verifiable the observed practice of collecting information about agents before contracting is inferior to writing contingent contracts. This holds regardless of the agent's risk aversion, bounded penalties, or investigation costs. In fact, with risk-neutral agents, a principal can get first-best utility with contingent contracts. We further show that even unverifiable signals can be gainfully used in contingent contracts by removing a principal's incentives to distort signals or by removing an agent's incentives to demand verification.
\end{abstract}




\section{Introduction}

Verifiability is an important attribute of accounting data. APB Statement No. 4 states: "Verifiable financial accounting information provides results that would be substantially duplicated by independent measurers using the same measurement methods" (paragraph 90). We model accounting data as a noisy signal about an agent's type in an adverse-selection setting and analyze how verifiability affects the data's use in contracts. Adverse selection is a common situation in which an agent (he) knows his type, which the principal (she) cannot observe when offering contracts. ${ }^{1}$ Verifiability is typically not analyzed in these settings because it is often implicitly assumed that an agent's report of an unverifiable signal adds no information beyond the agent's report of his type. $^{2}$ This is indeed true when an agent generates the signal and can freely manipulate it.

There are many adverse selection settings, however, where a principal or a third party generates the signal. For example, a bank can check a borrower's credit, and regulators can audit a defense contractor or a public utility to verify their claims of costs. We show that these settings offer a richer set of possibilities of using signals, especially unverifiable signals.

We start by pointing out the simplest way in which principals use unverifiable signals - to update their priors before offering contracts. Venture capitalists routinely interview an inventor before investing, and banks assess an applicant's creditworthiness before offering a loan. We call this ex-ante investigation (see Figure 1a). Since ex-ante investigation is commonly used, it is the benchmark for other alternatives. Ex-ante investigation also seems to be the optimal policy because the principal is "armed" with information before negotiating with the agent.

We then examine contracts in which the principal and the agent commit to a menu of contracts, and then the signal is generated to pick a contract from this menu. We call this ex-post investigation (see Figure 1b). Ex-post investigation appears infeasible with unverifiable signals because the agent will not trust the signal generated by the principal or will dispute the signal anyway if it contradicts his earlier reports. Even if the signal is verifiable, ex-post investigation appears inferior because the principal gets the signal later than in ex-ante investigation. We refute these seemingly intuitive arguments.

\footnotetext{
${ }^{1}$ For example, see analyses of the value of communication [Melumad and Reichelstein (1987) and Fellingham and Young (1990)] participative budgeting [Demski and Feltham (1978), Baiman and Evans (1983), Kirby, Reichelstein, Sen and Paik (1991), and Kanodia (1993)], public utilities regulation [Baron and Myerson (1982)], defense procurement [Reichelstein (1992)], and auditors' legal liability [Melumad and Thoman (1990)]. Our setting differs from informed-principal settings [Demski and Sappington (1991) and Myerson (1983)] in which the principal knows something about the agent's type that the agent does not know.

${ }^{2}$ Verifiability has been examined in settings in which the agent has no private information when contracting [Hermalin and Katz (1991), Demski and Sappington (1993), Dunne and Loewenstein (1995), and Arya and Glover (1996)]. The signal indicates the agent's effort after contracting or the production function [Cremer and Khalil (1992), Baiman and Sivaramakrishnan (1991), and Christensen and Feltham (1997)].
} 
Our contribution lies in formulating a simple model that provides three insights into how verifiability determines investigation policy. ${ }^{3}$ First, in contrast to the popular perception, we show that ex-post investigation strictly dominates ex-ante investigation when signals are verifiable, i.e., the principal is better off not getting signals before contracting. This is not because ex-post investigation lowers expected investigation costs via probabilistic investigation. In fact, investigation costs have no effect. In ex-post investigation, eliciting the truth is cheaper because the agent does not know the signal when signing the contract. In contrast, in ex-ante investigation the agent can infer the signal from the contracts offered, which reduces the signal's effectiveness in eliciting the truth. This holds regardless of the agent's risk aversion. With risk-neutral agents, the principal can achieve the first-best utility with ex-post investigation.

Second, we point out that ex-ante investigation can be used with unverifiable signals, while ex-post investigation requires verifiable signals, as it creates a potential conflict when the signal contradicts the agent. The principal thus may prefer a noisy but verifiable signal if it allows ex-post investigation. This captures one aspect of the relevance versus reliability trade-off in accounting.

Third, we show two modified ex-post contracts that can use even unverifiable signals. If the agent does not "trust" the signal generated by the principal, the principal can make the signal credible by designing contracts that make herself indifferent to the signal. We show that this modification dominates ex-ante investigation. Alternatively, if the agent trusts the signal generated by a neutral third party, but still demands verification when the signal contradicts him, the principal can make the agent indifferent to the signal and yet do better than ex-ante investigation. The trick lies in making only an honest agent indifferent to the signal.

We conclude by speculating on the popularity of ex-ante investigation in spite of its theoretical inferiority. Ex-ante investigation is simpler because a principal observes the signal first and need not design contracts for other signal realizations. Ex-post investigation requires the complete menu of contracts. In addition, ex-ante investigation, being similar to dominant-strategy implementation, does not require common knowledge of beliefs, information structure, and rationality, which the ex-post investigation, being similar to Bayesian-Nash implementation, requires.

Section 2 describes the basic model. Section 3 describes ex-ante investigation, the benchmark against which contingent contracts are compared. Section 4 proves that ex-post investigation is optimal and can achieve first-best utility with risk-neutral agents. Section 5 proposes two new modifications to ex-post investigation to use unverifiable signals. Section 6 describes the implications of our analysis and concludes the paper.

\footnotetext{
${ }^{3}$ Ex-ante investigation is infeasible if the signal concerns the agent's actions taken after contracting or is reported by the agent only after contracting. These settings cover most of the prior literature.
} 


\section{Model}

We model a risk-neutral principal who specifies the production level $(X)$ and compensation $(R)$ for an agent who knows his productivity (type), which is either $\theta_{L}$ or $\theta_{H}$. One can also view $X$ as the interest rate and $R$ as the magnitude of a loan, or $X$ as the premium and $R$ as the amount of insurance coverage. The principal can neither observe the agent's type nor infer it from the output. The agent's utility is $U(R)$, where $U^{\prime}>0, U^{\prime \prime} \leq 0$. His reservation utility is assumed to be 0 without loss of generality.

The agent can produce $X$ with certainty by incurring a disutility $D(X, \theta) . D$ is strictly increasing and strictly convex in $X$ and strictly decreasing in $\theta$; i.e., a low-type agent is less productive than a high-type agent $\left[D_{x}(\cdot, \cdot)>0, D_{x x}(\cdot, \cdot)>0\right.$, and $\left.D\left(X, \theta_{L}\right)>D\left(X, \theta_{H}\right) \forall X\right]$. The agent's indifference curves satisfy the single-crossing property. Specifically, the marginal disutility is strictly decreasing in $\theta\left[D_{x}\left(X, \theta_{L}\right)>D_{x}\left(X, \theta_{H}\right) \forall X\right]$. To avoid corner solutions, we assume $D_{x}(0, \cdot)=0$. We also assume strictly convex disutility so that the agent's indifference curves are convex. To understand how contracts depend on a principal's priors about an agent's type, we briefly examine the first-best and second-best solutions when the principal has no signals about the agent.

First-best: If the principal could observe the agent's type, she would specify $\left(X_{j}, R_{j}\right)$, where $j$ is the agent's type, and solve the following problem:

$$
\begin{aligned}
E P & =\sum_{j=L, H} \operatorname{prob}\left[\theta=\theta_{j}\right] E P\left[\theta=\theta_{j}\right] \\
\text { where } E P\left[\theta=\theta_{j}\right] \equiv & \max _{X_{j}, R_{j}}\left(X_{j}-R_{j}\right) \\
\text { s.t. } & U\left(R_{j}\right)-D\left(X_{j}, \theta_{j}\right) \geq 0,
\end{aligned}
$$

The principal offers $F B_{L}$ to the low-type agent where her indifference curve is tangent to his reservation utility curve (figure 2, curve 1). Similarly, the high-type agent's contract is $F B_{H}$ (figure 2, curve 5).

Second-best: If the principal cannot observe the agent's type and offers $F B_{H}$ and $F B_{L}$, then the high-type agent will claim to be a low-type agent. The principal therefore solves the following program to induce the agent to reveal his type (Myerson, 1979):

$$
\begin{array}{rlr}
E P \equiv \max _{X_{j}, R_{j}} \sum_{j=L, H} \operatorname{prob}\left[\theta=\theta_{j}\right]\left(X_{j}-R_{j}\right) & \\
\text { s.t. } & U\left(R_{j}\right)-D\left(X_{j}, \theta_{j}\right) \geq 0 & \forall j \\
& U\left(R_{j}\right)-D\left(X_{j}, \theta_{j}\right) \geq U\left(R_{\hat{\jmath}}\right)-D\left(X_{\hat{\jmath}}, \theta_{j}\right) \quad \hat{\jmath} \neq j \quad \forall j
\end{array}
$$


If the principal offers $F B_{L}$ (figure 2) to the low-type agent, then to satisfy $\mathrm{IC}_{H}$ she must offer the high-type agent a point on or above his indifference curve passing through $F B_{L}$; for optimality, the principal would pick the point at which her indifference curve is tangent to the high-type agent's indifference curve. The principal can squeeze the high-type agent by moving his contract closer to $F B_{H}$, but then she would have to move the low-type agent's contract away from $F B_{L}$ (towards the origin). The principal trades off deviating from the low-type agent's first-best against deviating from the high-type agent's first-best and offers $S B_{L}$ and $S B_{H}$ (figure 2, curve 3). As shown by the lemma below, the higher her prior that the agent is a low-type agent $\left(\operatorname{prob}\left[\theta=\theta_{L}\right]\right)$, the less she deviates from the low-type agent's first-best.

\section{Lemma 1}

1. $X_{L}$ is strictly increasing in $\operatorname{prob}\left[\theta=\theta_{L}\right]$.

2. $R_{L}$ is strictly increasing in $\operatorname{prob}\left[\theta=\theta_{L}\right]$.

3. $X_{H}$ is decreasing (strictly if $\left.U^{\prime \prime}<0\right)$ in $\operatorname{prob}\left[\theta=\theta_{L}\right]$.

4. $R_{H}$ is increasing (strictly if $D_{x x}>0$ ) in $\operatorname{prob}\left[\theta=\theta_{L}\right]$.

Proof: See the Appendix.

\section{Getting Signals Before Contracting: The Benchmark Case}

Principals often acquire signals about the agents to update their priors. For example, investors analyze financial statements before investing, employers interview employees before hiring, and banks check credit before giving a loan. We call this ex-ante investigation and use it as the benchmark against which we compare other ways of using signals. Suppose the principal can get a noisy signal $S \epsilon\left\{S_{L}, S_{H}\right\}$ that is positively correlated with the agent's type $\theta$ such that $\operatorname{prob}\left[S=S_{L} \mid \theta=\theta_{L}\right]=\operatorname{prob}\left[S=S_{H} \mid \theta=\theta_{H}\right]=p$, where $p$ is the signal's informativeness $[0.5<p<1]$.

In ex-ante investigation, after observing a low signal the principal offers the two contracts shown by the upper branch of Figure 1a. The output and compensation are denoted by $X_{i j}$ and $R_{i j}$, where $i$ refers to the signal and $j$ refers to the agent's type. The agent's choice depends on his type. Similarly, after observing a high signal, the principal offers the two contracts shown by the lower branch of Figure 1a. In this program, the principal sees the signal and offers a contract based on the updated priors.

(insert Figure 1 about here.) 
Ex-Ante Investigation - Program ${ }_{E x-A n t e}$ : Let $\operatorname{EP}\left[S=S_{i}\right]$ be the principal's expected profit conditional on $S=S_{i}$. She solves:

$$
\begin{array}{rlr}
E P\left[S=S_{i}\right] \equiv \max _{X_{i j}, R_{i j}} \sum_{j=L, H} \operatorname{prob}\left[\theta=\theta_{j} \mid S=S_{i}\right]\left(X_{i j}-R_{i j}\right) & \\
\text { s.t. } & \left(U\left(R_{i j}\right)-D\left(X_{i j}, \theta_{j}\right)\right) \geq 0 & \forall j \\
& \left(U\left(R_{i j}\right)-D\left(X_{i j}, \theta_{j}\right)\right) \geq\left(U\left(R_{i \hat{\jmath}}\right)-D\left(X_{i \hat{\jmath}}, \theta_{j}\right)\right) \quad \hat{\jmath} \neq j \quad \forall j
\end{array}
$$

The principal's unconditional expected profit is $E P=\sum_{i=L, H}\left\{\operatorname{prob}\left[S=S_{i}\right] E P\left[S=S_{i}\right]\right\}$. Constraints IRij and ICij are respectively the individual rationality and incentive compatibility constraint for a j-type agent when the signal is $S_{i}$. The contract for each signal realization is similar to the second-best contract except that the principal's priors are updated by the signal. As the following lemma shows, a low signal raises the probability that the agent is a low-type agent and moves the low-type agent's contract closer to his first best.

\section{Lemma 2}

1. $X_{L L}>X_{H L}, R_{L L}>R_{H L}$.

2. $X_{L H}<X_{H H}$ if $U^{\prime \prime}<0$ or $X_{L H}=X_{H H}$ if $U^{\prime \prime}=0$.

3. $R_{L H}>R_{H H}$ if $D_{x x}>0$ or $R_{L H}=R_{H H}$ if $D_{x x}=0$.

Proof: Follows from lemma 1 as $\operatorname{prob}\left[\theta=\theta_{L} \mid S_{i}=S_{L}\right]>\operatorname{prob}\left[\theta=\theta_{L} \mid S_{i}=S_{H}\right]$

(insert Figure 2 about here.)

On observing $S_{L}$ (figure 2 , curve 2 ), the principal offers $\left(X_{L L}, R_{L L}\right)$ and $\left(X_{L H}, R_{L H}\right)$. The low-type agent prefers $\left(X_{L L}, R_{L L}\right)$ while the high-type agent is indifferent and is assumed to pick $\left(X_{L H}, R_{L H}\right)$. This contract is similar to the second best, except that it is closer to low-type agent's first-best and further away from the high-type agent's first-best because $S_{L}$ raises the probability that the agent is a low- type agent. Similarly, on observing $S_{H}$ (figure 2, curve 4), the principal offers $\left(X_{H L}, R_{H L}\right)$ and $\left(X_{H H}, R_{H H}\right)$, which are closer to the high-type agent's first-best contract.

\section{Writing Contingent Contracts}

Instead of investigating before contracting, the principal can offer contracts that are contingent on the signal observed ex post, i.e., after the agent signs a contract but before he works. In expost investigation (Figure 1b), each contingent contract, shown by a grey rectangle, is a set of 
two output-compensation pairs. The agent chooses a set. The actual output-compensation pair is determined by the realized signal. The important issue here is that the agent can neither observe nor infer the signal when choosing contracts and cannot quit after the signal is realized. The principal solves the following program:

Ex-Post Investigation - Program Ex-Post-1 $_{1}$

$$
\begin{array}{ll}
E P \equiv & \max _{X_{i j}, R_{i j}} \sum_{j=L, H} \sum_{i=L, H}\left\{\operatorname{prob}\left[S=S_{i} \mid, \theta=\theta_{j}\right]\left(X_{i j}-R_{i j}\right)\right\} \\
\text { s.t. } & \sum_{i=L, H}\left\{\operatorname{prob}\left[S=S_{i} \mid \theta=\theta_{j}\right]\left(U\left(R_{i j}\right)-D\left(X_{i j}, \theta_{j}\right)\right)\right\} \geq 0 \quad \forall j \\
& \sum_{i=L, H}\left\{\operatorname{prob}\left[S=S_{i} \mid \theta=\theta_{j}\right]\left(U\left(R_{i j}\right)-D\left(X_{i j}, \theta_{j}\right)\right)\right\} \geq \\
& \sum_{i=L, H}\left\{\operatorname{prob}\left[S=S_{i} \mid \theta=\theta_{j}\right]\left(U\left(R_{i \hat{\jmath}}\right)-D\left(X_{i \hat{\jmath}}, \theta_{j}\right)\right)\right\} \quad \hat{\jmath} \neq j \quad \forall j
\end{array}
$$

Once ex-post investigation is formulated, its weak dominance over ex-ante investigation is easy to see. In Program $_{E x-A n t e}$, the constraints must be satisfied separately for every realization of

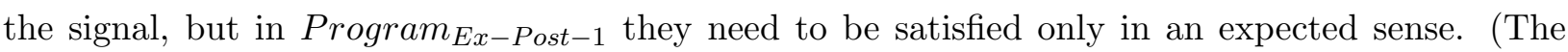
constraint IRj in Program $_{E x-P o s t-1}$ is an expectation of the constraints IRij in Program Px-Ante. $_{\text {. }}$ This extends to ICj as well.) The added flexibility can only benefit the principal. ${ }^{4}$ We now highlight two effects that make ex-post investigation strictly dominate ex-ante investigation. These effects form the basis of our results about unverifiable signals later in the paper.

\subsection{The Incentive Effect}

The incentive effect arises because in ex-post investigation the individual rationality constraints need to be met only in an expected sense. This effect is easiest to see for a risk-neutral agent. The next proposition shows that for a risk-neutral agent the incentive effect not only makes contingent contracts better than ex-ante investigation, it permits the principal to achieve first-best utility.

Proposition 1 For a risk-neutral agent, the principal's utility in Program $m_{E x-P o s t-1}$ equals her first-best utility, while her utility in Program ${ }_{E x-A n t e}$ is strictly less.

Proof: See the Appendix.

\footnotetext{
${ }^{4}$ This relates to the multi-agent literature [Demski and Sappington (1984), Demski, Sappington and Spiller (1988), and Rajan (1992)], where an agent's report serves as a signal about another agent's type. In sequential reporting

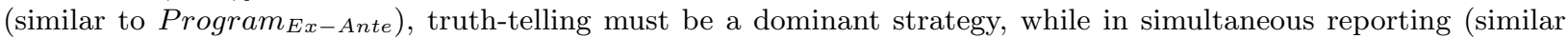
to Program Ex-Post-1) $_{\text {) }}$ truth-telling need only be a Bayesian-Nash equilibrium. Since dominant strategy constraints are stricter, the result obtains.
} 
In Program ${ }_{E x-A n t e}$, the IR constraints need to be satisfied for each signal, so in Figure 2 both $(\mathrm{L}, \mathrm{L})$ and $(\mathrm{H}, \mathrm{L})$ must lie on or above the low-type agent's reservation utility curve (curve 1), and $(\mathrm{L}, \mathrm{H})$ and $(\mathrm{H}, \mathrm{H})$ must lie on or above the high-type agent's reservation utility curve (curve 5). In Program $_{E x-P o s t-1}$, the IR constraints need to be satisfied only in an expected sense, so in Figure 3 the principal can deviate from the solution to Program $_{E x-A n t e}$ because now only the expected utility of $(\mathrm{L}, \mathrm{L})$ and $(\mathrm{H}, \mathrm{L})$ must lie on or above curve 1 . This allows her to penalize the low-type agent if the signal contradicts his report $(\mathrm{H}, \mathrm{L})$ and reward him otherwise $(\mathrm{L}, \mathrm{L})$.

(insert Figure 3 about here.)

Since the signal is positively correlated with the agent's true type, the probability of a reward $(\mathrm{L}, \mathrm{L})$ is higher for a low-type agent than for a high-type agent who claims to be a low-type agent. By increasing the distance between $(\mathrm{L}, \mathrm{L})$ and $(\mathrm{H}, \mathrm{L})$, the principal can reduce the high-type agent's rents while giving the reservation utility to the low-type agent. In fact, for risk-neutral agents the principal can eliminate the high-type agent's rents and achieve first best. ${ }^{5}$ We refer to this as the incentive effect of Program Px-Post-1. In other words, Program $_{E x-P o s t-1}$ imposes a lottery on the agent whose odds depend on the agent's type; a zero expected value lottery for the low-type agent has a negative expected value for the high-type agent, which allows the principal to use the lottery to separate the two types. Since risk-neutral agents demand no risk premium for facing the lottery, the principal can achieve first-best utility.

Since the ex-post investigation penalizes the agent if the signal contradicts him, it seems that the first best is infeasible if the compensation $(R)$ must be positive. ${ }^{6}$ The principal can, however, achieve first-best utility as long as the agent's total utility can be made sufficiently negative when the signal contradicts him. As the appendix shows, the more informative the signal or the greater the difference in productivity, the lower the needed divergence between compensation levels in the two states of the lottery. The compensation needs to be negative to achieve first-best only when the signal is relatively uninformative or when the difference in productivity of the two agents is

\footnotetext{
${ }^{5}$ Proposition 1 relates to two strands in the literature. First, Kerschbamer (1994) shows that in the Demski, Sappington and Spiller (1988) model with risk-neutral agents the principal can costlessly replace Bayesian-Nash IC constraints with dominant-strategy IC constraints. Proposition 1 shows that this is not true for the IR constraints. The Bayesian-Nash IR constraints allow the principal to achieve first best, and the dominant- strategy IR constraints do not. We thank an anonymous referee for elucidating this point. Second, the result relates to Cremer and McLean (1988), who show that if risk-neutral bidders have correlated private values the seller can extract all the surplus from the bidders.

${ }^{6}$ For example, in an auction similar to the one in Cremer and McLean (1988), Demougin and Garvie (1991) show that the seller cannot extract the entire surplus if the penalties that can be imposed on the risk-neutral bidders are bounded.
} 
high. Even if first-best utility is not achievable due to bounded penalties, it is easy to see that ex-post investigation still strictly dominates ex-ante investigation when the agent is risk-neutral.

Risk-averse agents demand a risk premium for bearing the risk imposed by these incentives, which makes first-best infeasible. ${ }^{7}$ It is unclear whether the incentive effect can make ex-post investigation strictly superior, let alone achieve first-best, when agents are risk averse. The insurance effect discussed next, however, ensures the strict superiority of ex-post investigation when agents are risk averse.

\subsection{The Insurance Effect}

The insurance effect exists because in ex-post investigation the incentive compatibility constraints need to be met only in an expected sense while in ex-ante investigation they need to be met for each signal.

Proposition 2 With a risk-averse agent, the principal would strictly prefer to investigate later even if the penalties that can be imposed on the agent are bounded $(R \geq 0)$.

$$
(\text { Expected Profit })_{\text {Program }_{E x-P o s t-1}}>(\text { Expected Profit })_{\text {Program }_{E x-A n t e}}
$$

Proof: See the Appendix. ${ }^{8}$

(insert Figure 4 about here.)

Figure 4 and the proof of Proposition 2 for a risk-averse agent illustrate the insurance effect. Since in Program ${ }_{E x-A n t e}$ the IC constraints need to be satisfied for each signal, a high-type agent's contract for a given signal must lie on the high-type agent's indifference curve passing through the low-type agent's contract for that signal. The flexibility of Program $_{E x-P o s t-1}$ allows the principal to eliminate the high-type agent's risk by equating $(\mathrm{H}, \mathrm{H})$ and $(\mathrm{L}, \mathrm{H})$ while keeping the high-type agent's expected utility unchanged. Now the high-type agent does not demand a risk premium. Bounded penalties do not eliminate this effect because both agents get positive compensation. The insurance effect also holds if $U(R)-D(X, \theta) \geq 0$ because both agents get non-negative utility in every state of the signal.

\footnotetext{
${ }^{7}$ A related result is in Robert (1991), who extends Cremer and McLean (1988) to risk-averse bidders and shows that the seller can no longer capture the entire surplus.

${ }^{8}$ This shows that replacing Bayesian-Nash IC constraints with dominant-strategy IC constraints is not costless with risk-averse agents, as it is with risk-neutral agents in Kerschbamer (1994).
} 
Note that the superiority of ex-post investigation is not based on the possibility of probabilistic investigation. In ex-ante investigation, the principal always investigates, by definition. In contrast, ex-post investigation permits probabilistic investigation. Our results are based on Program $_{E x-P o s t-1}$, in which the probability of investigation is constrained to be 1 . Allowing probabilistic investigation increases principal's flexibility and can only make her better off.

A combination of the incentive and insurance effects makes ex-post investigation, i.e., not getting the signal earlier, optimal for the principal regardless of the agent's risk aversion.

\subsection{The Impact of Verifiability}

The popularity of ex-ante investigation is surprising given its theoretical inferiority to ex-post investigation. Is this merely suboptimal behavior, or is it driven by something else? We show that verifiability plays a key role in the popularity of ex-ante investigation.

Program $_{E x-\text { Ante }}$ obviates the need for verification. The principal gets the signal before contracting. Although the contracts reflect the principal's updated priors, they are not contingent on a signal to be observed later. The principal therefore has no reason to manipulate the signal, and the agent has no opportunity to demand verification.

In contrast, as shown by figure 3, Program ${ }_{E x-P o s t-1}$ needs a verifiable signal. The principal's utility if the signal is high exceeds her utility if the signal is low. (The principal's utility increases in the southeast direction.) Both types of agents prefer a low signal. This difference in preferences creates a demand for verification in Program Ex-Post-1. $_{\text {. }}$

Since ex-post investigation is more effective than ex-ante investigation, principals may prefer a noisier but verifiable signal to a more accurate but unverifiable signal. For example, banks routinely exclude financial statement items that they consider difficult to verify. The IRS also frequently uses the cash method over the accrual method because cash flows are easier to verify.

Ex-post investigation appears infeasible with unverifiable signals. To the contrary, we now show that we can modify ex-post investigation to permit the use of unverifiable signals.

\section{Using Unverifiable Information in Contingent Contracts}

We turn to two modifications to ex-post investigation that allow the use of unverifiable signals. In the first setting, examined in Section 5.1, the signal is unverifiable because the principal observes it privately. For example, it could be the principal's subjective opinion based on an interview. We show that the principal can use such a signal in contingent contracts by ensuring that she has incentives to reveal the signal truthfully. In the second setting, examined in Section 5.2, the signal 
is produced by a neutral third party but is unverifiable. We show that the principal can use such a signal by removing the agent's incentives to demand verification.

\subsection{Committing to Honest Disclosure}

As discussed in Section 4.3, in Program $m_{E x-P o s t-1}$ the principal has an incentive to misrepresent the signal. The agent will therefore not trust the signal, especially because he commits before the principal reveals the signal. (If the principal were to reveal the signal before asking the agent to

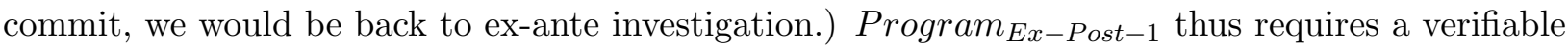
signal. It seems, therefore, that a signal that is privately observed by the principal cannot be used ex post. We show that a principal can still use the private signal ex post by making her report credible via two constraints (PIj) that make her indifferent to reporting either signal.

Program $_{E x-\text { Post-2: }}$

$$
\begin{array}{ll}
E P \equiv \max _{X_{i j}, R_{i j}} \sum_{j=L, H} \sum_{i=L, H}\left\{\operatorname{prob}\left[S=S_{i} \mid, \theta=\theta_{j}\right]\left(X_{i j}-R_{i j}\right)\right\} & \\
\text { s.t. } & \\
\sum_{i=L, H}\left\{\operatorname{prob}\left[S=S_{i} \mid \theta=\theta_{j}\right]\left(U\left(R_{i j}\right)-D\left(X_{i j}, \theta_{j}\right)\right)\right\} \geq 0 \quad \forall j \quad(\mathrm{IRj}) \\
\sum_{i=L, H}\left\{\operatorname{prob}\left[S=S_{i} \mid \theta=\theta_{j}\right]\left(U\left(R_{i j}\right)-D\left(X_{i j}, \theta_{j}\right)\right)\right\} \geq & \\
\sum_{i=L, H}\left\{\operatorname{prob}\left[S=S_{i} \mid \theta=\theta_{j}\right]\left(U\left(R_{i \hat{\jmath}}\right)-D\left(X_{i \hat{\jmath}}, \theta_{j}\right)\right)\right\} \quad \hat{\jmath} \neq j \quad \forall j \quad(\mathrm{ICj}) \\
X_{L j}-R_{L j}=X_{H j}-R_{H j} & \forall j \quad(\mathrm{PIj})
\end{array}
$$

If the solution of Program $_{E x-A n t e}$ were feasible under Program $_{E x-P o s t-2}$, the weak dominance of

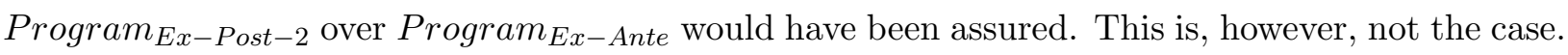
Suppose in Program $_{E x-P o s t-2}$ the agent is offered the contracts in Program $E x-A n t e$. If the agent reveals his type to be low, the principal has an incentive to report the signal as low to minimize the distortion in the low-type agent's contract from his first-best. Similarly, if the agent reveals his type to be high, the principal has an incentive to report the signal as high. This makes the contracts in Program $_{E x-\text { Ante violate the PI constraints in Program }}$ Ex-Post-2.

Equalizing the principal's payoffs across the two signal realizations eliminates her incentives to misreport a signal, but does it render the information useless? In other words, is the principal's

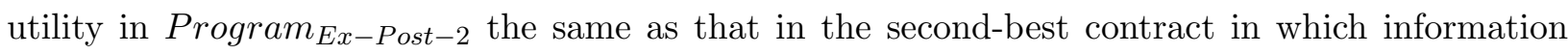
is not used at all? No, because the second-best contract has four implicit constraints, $X_{L j}=$ $X_{H j}=X_{j}$ and $R_{L j}=R_{H j}=R_{j}, \forall j$, but Program $_{E x-\text { Post-1 }}$ has only two constraints, $X_{L j}-$ 
$R_{L j}=X_{H j}-R_{H j}, \forall j .{ }^{9}$ Figure 5 shows the solution to Program $\operatorname{Pr}_{\mathrm{A}-\mathrm{Post}-2} ;\left(X_{H L}, R_{H L}\right)$ and $\left(X_{L L}, R_{L L}\right)$ are constrained to lie on the principal's indifference curve. For incentive compatibility, the expected utility of $\left(X_{H L}, R_{H L}\right)$ and $\left(X_{L L}, R_{L L}\right)$ to the high-type agent equals his expected utility for $\left(X_{H H}, R_{H H}\right)$ and $\left(X_{L H}, R_{L H}\right)$. [( $\left.X_{H H}, R_{H H}\right)$ now equals $\left(X_{L H}, R_{L H}\right)$ because they must now be on the same indifference line for the principal.]

(insert Figure 5 about here.)

Eliminating the need for verification in ex-post investigation is worthwhile only if it makes expost investigation better than ex-ante investigation. The following proposition shows that this is indeed the case.

Proposition 3 For a risk-neutral agent, Program Ex-Post-2 $_{\text {strictly dominates Program }}$ Ex-Ante $^{10}$

Proof: See the Appendix.

Figure 5 explains the intuition behind this result. We show that the principal can profitably

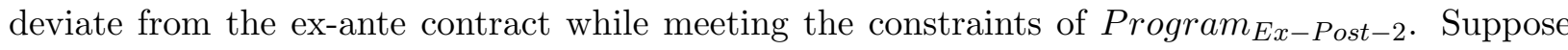
the principal offers the following contract to the low-type agent: $\hat{X}_{H L}=X_{H L}, \hat{X}_{L L}=X_{L L}$, $\hat{R}_{H L}<R_{H L}$, and $\hat{R}_{L L}>R_{L L}$, such that $\left(\hat{X}_{L L}, \hat{R}_{L L}\right)$ and $\left(\hat{X}_{H L}, \hat{R}_{H L}\right)$ are on the same indifference curve of the principal (a 45 degree line) and the low-type agent's expected utility is unchanged [in the figure $p * b=(1-p) * a]$. The principal can now offer $\hat{X}_{H H}=X_{H H}$ and $\hat{R}_{L H}=\hat{R}_{H H}=$ $p R_{H H}+(1-p) R_{L H}-\gamma$ where $\gamma=p * a-(1-p) b$. Since $p * b=(1-p) * a, \gamma=\frac{(2 p-1) a}{p}$, which is positive because $p>\frac{1}{2}$. The principal therefore reduces the high-type agent's rents by offering a fair lottery to the low-type agent that has a negative expected value to the high-type agent. The principal is now indifferent to the realization of the signal for both types of agents.

\subsection{Making the Agent Indifferent}

The previous section showed that a principal can use a signal that she observes privately by removing incentives to misrepresent the signal. This section shows that a principal can use an unverifiable signal that is generated by a neutral third party by making the agent indifferent to the signal. In Program $_{E x-P o s t-1}$, the low-type agent has an incentive to contest the high signal realization (see

\footnotetext{
${ }^{9}$ The agent is not indifferent to the signal. Constraints that make both the principal and the agent indifferent to the signal render the signal useless.

${ }^{10}$ Numerical examples showing the validity of the proposition for a risk-averse agent are available upon request. Although we have no formal proof for a risk-averse agent, we have no counterexamples either.
} 
figure 3). Program ${ }_{E x-P o s t-3}$ imposes indifference constraints IDj on Program ${ }_{E x-P o s t-1}$ to remove an agent's incentives to ask for verification. Note that, in contrast to the previous section, now the principal is not indifferent to the signal. This is not an issue because a third party, not the principal, reports the signal.

Program $_{E x-P o s t-3}$ :

$$
\begin{aligned}
& E P \equiv \max _{X_{i j}, R_{i j}} \sum_{j=L, H} \sum_{i=L, H}\left\{\operatorname{prob}\left[S=S_{i} \mid, \theta=\theta_{j}\right]\left(X_{i j}-R_{i j}\right)\right\} \\
& \text { s.t. } \quad \sum_{i=L, H}\left\{\operatorname{prob}\left[S=S_{i} \mid \theta=\theta_{j}\right]\left(U\left(R_{i j}\right)-D\left(X_{i j}, \theta_{j}\right)\right)\right\} \geq 0 \quad \forall j \quad(\operatorname{IRj}) \\
& \sum_{i=L, H}\left\{\operatorname{prob}\left[S=S_{i} \mid \theta=\theta_{j}\right]\left(U\left(R_{i j}\right)-D\left(X_{i j}, \theta_{j}\right)\right)\right\} \geq \\
& \sum_{i=L, H}\left\{\operatorname{prob}\left[S=S_{i} \mid \theta=\theta_{j}\right]\left(U\left(R_{i \hat{\jmath}}\right)-D\left(X_{i \hat{\jmath}}, \theta_{j}\right)\right)\right\} \quad \hat{\jmath} \neq j \quad \forall j \quad(\mathrm{ICj}) \\
& U\left(R_{L j}\right)-D\left(X_{L j}, \theta_{j}\right)=U\left(R_{H j}\right)-D\left(X_{H j}, \theta_{j}\right) \quad \forall j \quad(\mathrm{IDj})
\end{aligned}
$$

Do the indifference constraints render the signal useless? The proposition below shows that not only are these contracts better than second-best, they always dominate ex-ante investigation.

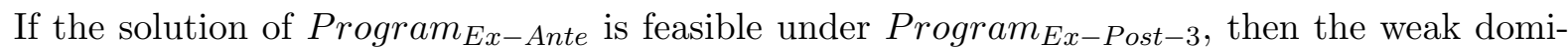
nance of Program ${ }_{E x-P o s t-3}$ over Program ${ }_{E x-A n t e}$ is assured. This is, however, not the case because the high-type agent is not indifferent to the signal realization if the contracts in Program $_{E x-a n t e}$ were offered in Program $E x-P o s t-3$. The high-type agent will prefer the signal to be low.

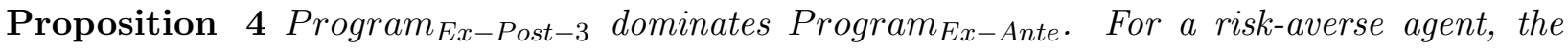
dominance is strict.

Proof: See the Appendix.

Making an agent indifferent to the signal after he reports his type still lowers the cost of eliciting truth from the agent because the principal makes only an honest agent indifferent. It

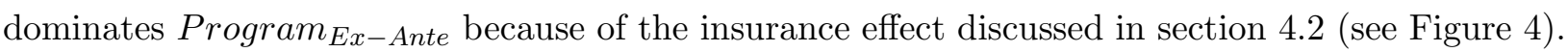
Consider how Program Px-Post-3 allows the principal to deviate from Program $_{E x-\text { Ante }}$ to improve her utility. The indifference constraints require the contracts for each type of agent to lie on the same indifference curve for both signal realizations. This already holds for the low-type agent in

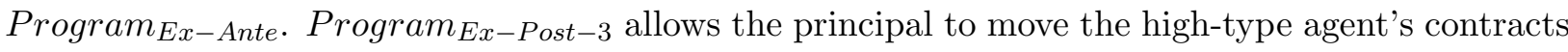
to the same indifference curve while ensuring that the high-type agent gets the same expected utility. Since the high-type agent faces no risk, the principal need not pay him a risk premium, which benefits her. 
We have analyzed a broad spectrum of contracts that highlight the crucial role of verifiability. In spite of our results, we rarely observe the above schemes. The next section discusses some of the possible reasons.

\section{$6 \quad$ Summary and Implications}

We study the impact of verifiability in an adverse selection setting in which accounting data are a noisy signal about an agent's type. The issue of verifiability has not been examined in adverse selection settings previously because the signal, if any, is assumed to be generated by the agent. If an agent generates an unverifiable signal about his type the signal is merely another report of his type. We examine settings that allow a rich analysis of verifiability because the principal or a third party generates the signal.

We make three contributions about how the commonly observed method of gathering information before contracting (ex-ante investigation) compares with other ways of using signals as the verifiability of the signal changes. First, using a simple model we show that, contrary to the popular perception, with verifiable signals ex-post investigation strictly dominates ex-ante investigation. All the usual suspects - bounded penalties, investigation costs, probabilistic investigation, informativeness of the signal, and the agent's risk aversion - do not affect this dominance, which arises because eliciting the truth is cheaper if the agent does know the signal when signing the contract. In fact, ex-post investigation permits first-best when agents are risk neutral. Second, we present a clear example of the relevance versus reliability trade-off in accounting by showing that a principal may prefer a noisy but verifiable signal because it makes ex-post investigation more effective. Third, we show that ex-post investigation is effective even with unverifiable signals. If the principal generates the signal, she can use the signal by ensuring that she is indifferent to its realization. If a third party generates the signal, the principal can make an honest agent indifferent to the signal.

We now speculate on why ex-ante investigation remains popular. Ex-ante investigation requires specifying contracts only for the observed signal. In contrast, ex-post investigation requires specifying the contracts for all signal realizations. Designing ex-ante contracts is thus less costly. The implementation literature provides further clues. Ex-ante investigation is a dominant-strategy implementation, as the agent is induced to tell the truth for every state of the signal, while ex-post investigation is a Bayesian-Nash implementation, as truth-telling is the agent's best response given his beliefs about the signal and requires common knowledge of the information structure, prior beliefs, and rationality. This is considered to be too demanding relative to the dominant-strategy 
implementation (Ledyard, 1986) Ex-ante investigation is thus "easy" and "robust."

The discussion above suggests that ex-post investigation is more likely under the following conditions. First, when signals are verifiable, e.g., firms hire employees on the condition that they will produce proof of the degrees that they claim to have. Second, when the principal can penalize the agent, e.g., government agencies such as the IRS audit tax returns after they are filed. Third, when investigation costs are high because ex-post investigation allows lowering expected investigation costs by investigating with probability less than one. Fourth, when the number of possible signal realizations is small because the cost of specifying the menu of contracts is lower. Fifth, when a principal interacts with agents frequently because the cost of designing ex-post contracts can be spread over a larger set of contracts.

Our analysis of verifiability also speaks to how detailed accounting disclosures should be. If financial statements are to include information that is difficult to verify, then parties that wish to use the more effective contingent contracts would prefer that such information be disclosed separately so that they can exclude it from their contracts. For example, disclosing the details of the assets enables banks to exclude intangible assets from computations of net worth in debt covenants. Disaggregated disclosure may be necessary from a contracting perspective even if aggregate numbers alone are sufficient for assessing stock prices. 


\section{Appendix}

Proof of Lemma 1: Let $\operatorname{prob}\left[\theta=\theta_{L}\right]=m$. Let $\left(X_{j}, R_{j}\right)$ be the optimal contract for probability $m$ and $\left(\hat{X}_{j}, \hat{R}_{j}\right)$ be the optimal contract for probability $m+\delta_{m}$, where $\delta_{m}>0$ and sufficiently small.

To show: $\hat{X}_{L}>X_{L}, \hat{R}_{L}>R_{L}, \hat{X}_{H} \leq X_{H}$, and $\hat{R}_{H} \geq R_{H}$.

Let us now study the solution at $m$. It is well known that $\mathrm{IR}_{H}$ and $\mathrm{IC}_{L}$ are non-binding, $\mathrm{IR}_{L}$ and $\mathrm{IC}_{H}$ are binding, and the following equalities hold.

$$
\begin{aligned}
U^{\prime}\left(R_{H}\right) & =D_{x}\left(X_{H}, \theta_{H}\right) \\
\left(1-\frac{D_{x}\left(X_{L}, \theta_{L}\right)}{U^{\prime}\left(R_{L}\right)}\right) & =\frac{(1-m)}{m D_{x}\left(X_{H}, \theta_{H}\right)}\left[D_{x}\left(X_{L}, \theta_{L}\right)-D_{x}\left(X_{L}, \theta_{H}\right)\right]
\end{aligned}
$$

By using the implicit function theorem on the first-order conditions and using the binding constraints, it can be shown that $\mathrm{X}, \mathrm{R}$ are continuous and differentiable in $m$. We will now study the solution at $m+\delta_{m}$. Assume the following relations:

$$
\begin{aligned}
& \hat{X}_{L}=X_{L}+\epsilon \\
& \hat{R}_{L}=R_{L}+\gamma \\
& \hat{X}_{H}=X_{H}-\beta \\
& \hat{R}_{H}=R_{H}+\alpha
\end{aligned}
$$

Taylor expansion of $\operatorname{IR}_{L}$ at $m+\delta_{m}$ implies: $\gamma=\frac{D_{x}\left(X_{L}, \theta_{L}\right)}{U^{\prime}\left(R_{L}\right)} \epsilon$.

Taylor expansion of $\mathrm{IC}_{H}$ at $m+\delta_{m}$, and substitution for the derivatives from Equation 1 and Equation 2 implies:

$$
\alpha+\beta=\left[\frac{D_{x}\left(X_{L}, \theta_{L}\right)-D_{x}\left(X_{L}, \theta_{H}\right)}{D_{x}\left(X_{H}, \theta_{H}\right)}\right] \epsilon .
$$

Since $\left(\hat{X}_{j}, \hat{R}_{j}\right)$ are optimal at $m+\delta_{m}$, the following must be true: $E P\left(\hat{X}_{j}, \hat{R}_{j}, m+\delta_{m}\right)-E P\left(X_{j}, R_{j}, m+\right.$ $\left.\delta_{m}\right)>0$ or, by substitution,

$$
\epsilon\left[\left(m+\delta_{m}\right)\left[1-\frac{D_{x}\left(X_{L}, \theta_{L}\right)}{U^{\prime}\left(R_{L}\right)}\right]-\left(1-m-\delta_{m}\right)\left[\frac{D_{x}\left(X_{L}, \theta_{L}\right)-D_{x}\left(X_{L}, \theta_{H}\right)}{D_{x}\left(X_{H}, \theta_{H}\right)}\right]\right]>0
$$

Substitution from equation 2 gives,

$$
\epsilon\left\{\frac{D_{x}\left(X_{L}, \theta_{L}\right)-D_{x}\left(X_{L}, \theta_{H}\right)}{D_{x}\left(X_{H}, \theta_{H}\right)}\right\}\left[\left(\frac{m+\delta_{m}}{m}\right)(1-m)-\left(1-m-\delta_{m}\right)\right]>0
$$

We know from the single crossing property that $D_{x}\left(X_{L}, \theta_{L}\right)-D_{x}\left(X_{L}, \theta_{H}\right)>0$. 
We can also see that $\left[\left(\frac{m+\delta_{m}}{m}\right)(1-m)-\left(1-m-\delta_{m}\right)\right]=\frac{\delta_{m}}{m}>0$. Thus, for (X,R) to be optimal, $\epsilon>0$, which implies the following:

- $\hat{X}_{L}>X_{L}$.

- $\gamma>0$, hence $\hat{R}_{L}>R_{L}$.

- $(\alpha+\beta)>0$ (using the single-crossing property). Taylor expansion of Equation 1 gives $\alpha U^{\prime \prime}\left(R_{H}\right)=-\beta D_{x x}\left(X_{H}, \theta_{H}\right)$, which further implies,

- if $U^{\prime \prime}=0$, then $\beta=0$ and $\alpha>0$.

- if $D_{x x}=0$, then $\alpha=0$ and $\beta>0$

(Both $U^{\prime \prime}$ and $D_{x x}$ cannot be zero by assumption of convex indifference curves.)

Hence, $\hat{X}_{H} \leq X_{H}$ and $\hat{R}_{H} \geq R_{H}$.

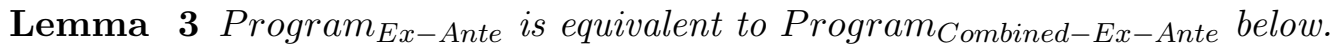

This lemma transforms the objective function of Program $_{E x-A n t e}$ to make it comparable with Program $_{E x-\text { Post }-1}$.

Program $_{\text {Combined-Ex-Ante }}$

$$
\begin{array}{llll}
E P \equiv & \max _{X_{i j}, R_{i j}} \sum_{j=L, H} \sum_{i=L, H}\left\{\operatorname{prob}\left[S=S_{i}, \theta=\theta_{j}\right]\left(X_{i j}-R_{i j}\right)\right\} & & \\
\text { s.t. } & U\left(R_{i j}\right)-D\left(X_{i j}, \theta_{j}\right) \geq 0 & & \forall i, j \quad \text { (IRij) } \\
& U\left(R_{i j}\right)-D\left(X_{i j}, \theta_{j}\right) \geq U\left(R_{i \hat{\jmath}}\right)-D\left(X_{i \hat{\jmath}}, \theta_{j}\right) & \hat{\jmath} \neq j & \forall i, j \quad \text { (ICij) }
\end{array}
$$

Note that the objective function of this program is the same as that of Program Px-Post-1. $_{\text {. }}$

Proof: The principal's expected profit in Program $_{E x-A n t e}$ is

$$
E P=\sum_{i=L, H}\left\{\operatorname{prob}\left[S=S_{i}\right] E P\left[S=S_{i}\right]\right\}
$$

where $E P\left[S=S_{i}\right]$ is the maximized expected profit if the signal produced by the information system is $S=S_{i}$, subject to the four constraints [IRij,ICij for $\mathrm{j}=\mathrm{L}, \mathrm{H}$ ]. The constrained problem for $S_{i}=S_{L}$ is independent of the problem for $S_{i}=S_{H}$; i.e., the constraints and the objective function have no common choice variables. We can thus equivalently maximize the objective function given by $E P$, subject to all eight constraints [IRij,ICij for $\mathrm{i}, \mathrm{j}=\mathrm{L}, \mathrm{H}]$, because it is a linear combination of $E P\left[S=S_{L}\right]$ and $E P\left[S=S_{H}\right]$ with strictly positive weights. By using Bayes' rule, $E P$ can be written as the objective function of Program Combined-Ex-Ante. $_{\text {. }}$ 


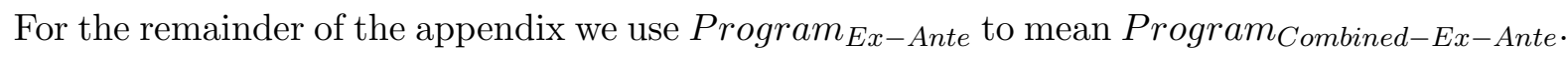

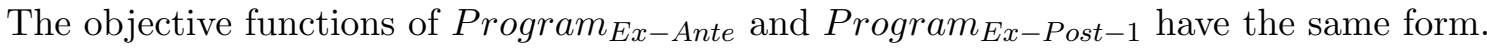

\section{Proof of Proposition 1}

We show that the principal can induce the same production as the first-best solution and make the same expected payments as in the first-best solution.

Let $\left(X_{H}^{F B}, R_{H}^{F B}\right)$ and $\left(X_{L}^{F B}, R_{L}^{F B}\right)$ be the first-best solution. Consider $\left(\widehat{X}_{i j}, \widehat{R}_{i j}\right)$ for $i, j \in$

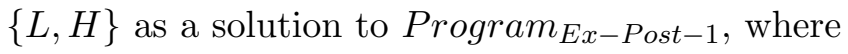

$$
\begin{aligned}
\widehat{X}_{L H} & =\widehat{X}_{H H}=X_{H}^{F B} \\
\widehat{X}_{L L} & =\widehat{X}_{H L}=X_{L}^{F B}
\end{aligned}
$$

To highlight that this result is due to relaxation of IR constraints alone, we assume that the IC constraints are the same as the ex-ante program and relax the IR constraints. We need to prove that there exist $\widehat{R}_{i j}$ for $i, j \in\{L, H\}$ such that the following constraints are satisfied.

$$
\begin{array}{rlr}
\widehat{R}_{H H}-D\left(X_{H}^{F B}, \theta_{H}\right) & \geq \widehat{R}_{H L}-D\left(X_{L}^{F B}, \theta_{H}\right) & \left(\mathrm{IC}_{\mathrm{HH}}\right) \\
\widehat{R}_{L H}-D\left(X_{H}^{F B}, \theta_{H}\right) & \geq \widehat{R}_{L L}-D\left(X_{L}^{F B}, \theta_{H}\right) & \left(\mathrm{IC}_{\mathrm{LH}}\right) \\
\widehat{R}_{L L}-D\left(X_{L}^{F B}, \theta_{L}\right) & \geq \widehat{R}_{L H}-D\left(X_{H}^{F B}, \theta_{L}\right) & (\mathrm{IC} \mathrm{LL}) \\
\widehat{R}_{H L}-D\left(X_{L}^{F B}, \theta_{L}\right) & \geq \widehat{R}_{H H}-D\left(X_{H}^{F B}, \theta_{L}\right) & \left(\mathrm{IC}_{\mathrm{HL}}\right) \\
p \widehat{R}_{H H}+(1-p) \widehat{R}_{L H} & \geq D\left(X_{H}^{F B}, \theta_{H}\right) & \left(\mathrm{IR}_{\mathrm{H}}\right) \\
p \widehat{R}_{L L}+(1-p) \widehat{R}_{H L} & \geq D\left(X_{L}^{F B}, \theta_{L}\right) & \left(\mathrm{IR}_{\mathrm{L}}\right)
\end{array}
$$

We solve for $\widehat{R}_{i j}$ assuming that the $\mathrm{IC}_{\mathrm{HH}}, \mathrm{IC}_{\mathrm{LH}}, \mathrm{IR}_{\mathrm{H}}$ and $\mathrm{IR}_{\mathrm{L}}$ are binding and show that the solution satisfies $\mathrm{IC}_{\mathrm{LL}}$ and $\mathrm{IC}_{\mathrm{HL}}$. The binding constraints imply the following:

$$
\begin{aligned}
\widehat{R}_{L H} & =D\left(X_{H}^{F B}, \theta_{H}\right)+\frac{p}{(2 p-1)}\left(D\left(X_{L}^{F B}, \theta_{L}\right)-D\left(X_{L}^{F B}, \theta_{H}\right)\right) \\
\widehat{R}_{H H} & =D\left(X_{H}^{F B}, \theta_{H}\right)-\frac{(1-p)}{(2 p-1)}\left(D\left(X_{L}^{F B}, \theta_{L}\right)-D\left(X_{L}^{F B}, \theta_{H}\right)\right) \\
\widehat{R}_{L L} & =\frac{p D\left(X_{L}^{F B}, \theta_{L}\right)-(1-p) D\left(X_{L}^{F B}, \theta_{H}\right)}{(2 p-1)} \\
\widehat{R}_{H L} & =\frac{p D\left(X_{L}^{F B}, \theta_{H}\right)-(1-p) D\left(X_{L}^{F B}, \theta_{L}\right)}{(2 p-1)}
\end{aligned}
$$


By substitution $\left(\mathrm{IC}_{\mathrm{LL}}\right)$ is satisfied if

$$
\begin{gathered}
D\left(X_{H}^{F B}, \theta_{L}\right)-D\left(X_{L}^{F B}, \theta_{L}\right) \geq D\left(X_{H}^{F B}, \theta_{H}\right)-D\left(X_{L}^{F B}, \theta_{H}\right) \\
\Leftrightarrow D\left(X_{L}^{F B}, \theta_{L}\right)+\int_{X_{L}^{F B}}^{X_{H}^{F B}} D_{X}\left(t, \theta_{L}\right) d t-D\left(X_{L}^{F B}, \theta_{L}\right) \geq D\left(X_{L}^{F B}, \theta_{H}\right)+\int_{X_{L}^{F B}}^{X_{H}^{F B}} D_{X}\left(t, \theta_{H}\right) d t-D\left(X_{L}^{F B}, \theta_{H}\right) \\
\Leftrightarrow \int_{X_{L}^{F B}}^{X_{H}^{F B}} D_{X}\left(t, \theta_{L}\right) d t \geq \int_{X_{L}^{F B}}^{X_{H}^{F B}} D_{X}\left(t, \theta_{H}\right) d t
\end{gathered}
$$

Given that $X_{H}^{F B}>X_{L}^{F B}$, the last inequality is implied by the assumed single-crossing property $\left[D_{X}\left(t, \theta_{L}\right)>D_{X}\left(t, \theta_{H}\right) \forall X\right]$. Similarly, it can be shown that $\left(\mathrm{IC}_{\mathrm{Hl}}\right)$ is also satisfied by the above solution. We have shown that the principal can implement $X_{H}>X_{L}$ and keep both IR constraints binding. Her expected profits will be maximized at the first best output levels. Also note that,

$$
\widehat{R}_{L L}-\widehat{R}_{H L}=\frac{D\left(X_{L}^{F B}, \theta_{L}\right)-D\left(X_{L}^{F B}, \theta_{H}\right)}{(2 p-1)}
$$

The numerator of RHS $>0$ because the high-type agent is more productive. The denominator of RHS $>0$ because $\mathrm{p}>\frac{1}{2}$. A feasible solution thus has $\widehat{R}_{L L}>\widehat{R}_{H L}$. The difference between the compensation levels increases as the difference between the productivity of the two types increases or the informativeness of the signal (p) decreases. Also note that since $D\left(X_{L}^{F B}, \theta_{H}\right)<D\left(X_{L}^{F B}, \theta_{L}\right)$, $\widehat{R}_{H L}$ can be less than 0 . We thus have shown that by just relaxing the IR constraints a feasible solution exists where the first-best production level is achieved and risk-neutral agents get no rents, so the principal gets her first-best level of utility.

Proof of Proposition 2: The proof is based on taking suitable deviations from the optimal solution in Program $_{E x-A n t e}$ and showing that such deviations are feasible in Program $_{E x-P o s t-1}$ and lead to a strict improvement in the principal's expected utility. Let $\hat{X}_{i j}, \hat{R}_{i j}$ be optimal in Program Px-Ante. By Lemma 3, the objective function of Program $_{E x-P o s t-1}$ evaluated at $\hat{X}_{i j}, \hat{R}_{i j}$ is equal to that of Program $_{E x-A n t e}$. The IR constraints of Program P $x-$ Post-1 $_{\text {are also }}$ satisfied at $\hat{X}_{i j}, \hat{R}_{i j}$, since $\operatorname{IRj}_{\text {Program }_{E x-P o s t}}=\sum_{i=L, H} \operatorname{prob}\left[S=S_{i} \mid \theta=\theta_{j}\right] \operatorname{IRij}_{\text {Program }_{E x-A n t e}}$. The

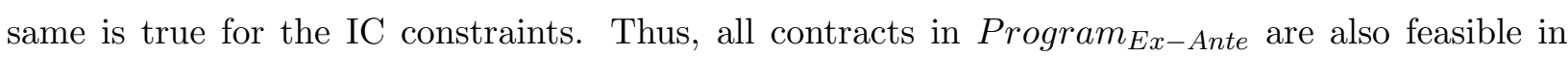
Program $_{E x-P o s t-1}$. This proves weak dominance. Strict dominance is proved below.

Let $m=\operatorname{prob}\left[\theta=\theta_{L}\right]$. We conjecture a contract for $\operatorname{Program}_{E x-P o s t-1}$ by equating $X_{i j}, R_{i L}$ to $\hat{X}_{i j}, \hat{R}_{i L}$ for $i=L, H$ and $R_{L H}=\hat{R}_{L H}-\epsilon, R_{H H}=\hat{R}_{H H}+\epsilon\left(\frac{(1-p)}{p}\right) \frac{U^{\prime}\left(\hat{R}_{L H}\right)}{U^{\prime}\left(\hat{R}_{H H}\right)}$ for $\epsilon>0$ and sufficiently small. We show that this conjectured deviation is feasible and strictly improves the principal's expected profit as compared to Program $_{E x-A n t e}$. 
The variables in $\mathrm{IR}_{L}$, the LHS of $\mathrm{IC}_{L}$, and the RHS of $\mathrm{IC}_{H}$ of Program $m_{E x-P o s t-1}$ are unchanged. Using Taylor's expansion, it can be shown that the conjectured deviation has zero net change on $\mathrm{IR}_{H}$ and the LHS of $\mathrm{IC}_{H}$ and strictly reduces the RHS of $\mathrm{IC}_{L}$. Thus, all the constraints are satisfied and expected profit changes by $(1-m)(1-p)\left[1-\frac{U^{\prime}\left(\hat{R}_{L H}\right)}{U^{\prime}\left(\hat{R}_{H H}\right)}\right] \epsilon$, which is strictly positive because $\frac{U^{\prime}\left(\hat{R}_{L H}\right)}{U^{\prime}\left(\hat{R}_{H H}\right)}<1$, from Lemma 2 , for a strictly risk-averse agent and a strictly convex disutility function.

The above deviations are feasible even if there are lower bounds on R. We know from Lemma 2 that $\hat{R}_{L H}>\hat{R}_{H H}$. The deviations are feasible $(R \geq 0)$ because they decrease $\hat{R}_{L H}$ (which is higher) and increase $\hat{R}_{H H}$.

Thus, the agent's utility over wealth is kept constant and the payments are moved closer together; because of concavity of U(.), this increases the principal's expected profits. Note that each of the IR constraints in Program ${ }_{E x-A n t e}$ are still met. The insurance effect thus arises from relaxing the IC constraints alone.

\section{Proof of Proposition 3:}

With a risk-neutral agent, let the optimal solution to the ex-ante program be $\left(X_{i j}, R_{i j}\right)$ for $i, j \in\{L, H\}$. We need to show that there exist $\left(\hat{X}_{i j}, \hat{R}_{i j}\right)$ that satisfy Program $_{E x-\text { Post-2 }}$ and make the principal better off. Using Equation (1) and the fact that $U^{\prime}(\cdot)$ is constant for the risk-neutral agent, we know that $X_{L H}=X_{H H}=X_{H}$. Suppose the principal considers the following solution to Program $_{E x-P o s t-2}$. The production levels are unchanged; i.e., $\hat{X}_{L L}=X_{L L}, \hat{X}_{H L}=X_{H L}$, $\hat{X}_{L H}=X_{H}$, and $\hat{X}_{H H}=X_{H}$. The agent's compensation, however, is changed as follows:

$$
\begin{aligned}
\hat{R}_{H H} & =\hat{R}_{L H}=p R_{H H}+(1-p) R_{L H}-\gamma \\
\hat{R}_{L L} & =\hat{X}_{L L}-\phi_{L} \\
\hat{R}_{H L} & =\hat{X}_{H L}-\phi_{L}
\end{aligned}
$$

where:

$$
\begin{aligned}
\phi_{L} & =p\left(X_{L L}-R_{L L}\right)+(1-p)\left(X_{H L}-R_{H L}\right) \\
\gamma & =\text { a small positive number restricted later. }
\end{aligned}
$$

We need to check whether $\left(\hat{X}_{i j}, \hat{R}_{i j}\right)$ satisfies the constraints of Program $E x-$ Post-2. Since $\hat{X}_{H H}=\hat{X}_{L H}$ and $\hat{R}_{H H}=\hat{R}_{L H}, \mathrm{PI}_{H}$ is trivially satisfied. $\mathrm{PI}_{L}$ is also satisfied by construction because $\hat{X}_{L L}-\hat{R}_{L L}=\phi_{L}=\hat{X}_{H L}-\hat{R}_{H L}$. 
To check $\mathrm{IR}_{L}$, substitute $\phi_{L}=p\left(X_{L L}-R_{L L}\right)+(1-p)\left(X_{H L}-R_{H L}\right)$, in the expression below:

$$
\begin{aligned}
& p\left(\hat{R}_{L L}-D\left(\hat{X}_{L L}, \theta_{L}\right)\right)+(1-p)\left(\hat{R}_{H L}-D\left(\hat{X}_{H L}, \theta_{L}\right)\right) \\
& =p\left(X_{L L}-\phi_{L}-D\left(X_{L L}, \theta_{L}\right)\right)+(1-p)\left(X_{H L}-\phi_{L}-D\left(X_{H L}, \theta_{L}\right)\right) \\
& =p X_{L L}+(1-p) X_{H L}-\phi_{L}-p D\left(X_{L L}, \theta_{L}\right)-(1-p) D\left(X_{H L}, \theta_{L}\right) \\
& =p R_{L L}+(1-p) R_{H L}-p D\left(X_{L L}, \theta_{L}\right)-(1-p) D\left(X_{H L}, \theta_{L}\right) \\
& =p\left(R_{L L}-D\left(X_{L L}, \theta_{L}\right)\right)+(1-p)\left(R_{H L}-D\left(X_{H L}, \theta_{L}\right)\right) \\
& =p * L H S \text { of } I R_{L L} \text { in Ex-ante }+(1-p) * L H S \text { of } I R_{H L} \text { in Ex-ante }=0
\end{aligned}
$$

To check $\mathrm{IR}_{H}$, note that

$$
\begin{aligned}
& (1-p)\left(\hat{R}_{L H}-D\left(\hat{X}_{L H}, \theta_{H}\right)\right)+p\left(\hat{R}_{H H}-D\left(\hat{X}_{H H}, \theta_{H}\right)\right) \\
& =p R_{H H}+(1-p) R_{L H}-\gamma-(1-p) D\left(X_{L H}, \theta_{H}\right)-p D\left(X_{H H}, \theta_{H}\right) \\
& =(1-p)\left(R_{L H}-D\left(X_{L H}, \theta_{H}\right)\right)+p\left(R_{H H}-D\left(X_{H H}, \theta_{H}\right)\right)-\gamma \\
& =(1-p) * I R_{L H} \text { in Ex-ante }+p * I R_{H H} \text { in Ex-ante }-\gamma
\end{aligned}
$$

Since $R_{L H}>R_{H H}$ (Lemma 1.4), $X_{L H}=X_{H H}$ (a consequence of risk-neutrality discussed above), and the IR constraints for the high-type agent are not binding in Program $_{E x-A n t e}$, there exists $\gamma>0$ such that $\mathrm{IR}_{H}$ in Program ${ }_{E x-P o s t-2}$ is not violated.

$\mathrm{IC}_{L}$ is satisfied as we have fixed the low-type agent's utility and reduced the high-type agent's utility.

To check $\mathrm{IC}_{H}$, we substitute for $\left(\hat{X}_{i j}, \hat{R}_{i j}\right)$ and show:

$$
\begin{aligned}
& (1-p)\left(\hat{R}_{L H}-D\left(\hat{X}_{L H}, \theta_{H}\right)\right)+p\left(\hat{R}_{H H}-D\left(\hat{X}_{H H}, \theta_{H}\right)\right) \\
& \geq(1-p)\left(\hat{R}_{L L}-D\left(\hat{X}_{L L}, \theta_{H}\right)\right)+p\left(\hat{R}_{H L}-D\left(\hat{X}_{H H}, \theta_{H}\right)\right) \\
& (1-p)\left(R_{L H}-D\left(X_{L H}, \theta_{H}\right)\right)+p\left(R_{H H}-D\left(X_{H H}, \theta_{H}\right)\right)-\gamma \\
& \geq(1-p)\left(X_{L L}-\phi_{L}-D\left(X_{L L}, \theta_{H}\right)\right)+p\left(X_{H L}-\phi_{L}-D\left(X_{H L}, \theta_{H}\right)\right) \\
& =(1-p) X_{L L}+p X_{H L}-\phi_{L}-(1-p) D\left(X_{L L}, \theta_{H}\right)-p D\left(X_{H L}, \theta_{H}\right) \\
& =(1-p) X_{L L}+p X_{H L}-p\left(X_{L L}-R_{L L}\right)-(1-p)\left(X_{H L}-R_{H L}\right)
\end{aligned}
$$




$$
\begin{aligned}
& -(1-p) D\left(X_{L L}, \theta_{H}\right)-p D\left(X_{H L}, \theta_{H}\right) \\
= & (1-2 p) X_{L L}-(1-2 p) X_{H L}+p R_{L L}+(1-p) R_{H L} \\
& \quad+(1-p)\left(R_{L L}-D\left(X_{L L}, \theta_{H}\right)\right)+p\left(R_{H L}-D\left(X_{H L}, \theta_{H}\right)\right)-(1-p) R_{L L}-p R_{H L} \\
= & (1-p)\left(R_{L L}-D\left(X_{L L}, \theta_{H}\right)\right)+p\left(R_{H L}-D\left(X_{H L}, \theta_{H}\right)\right) \\
& \quad-(2 p-1)\left[\left(X_{L L}-R_{L L}\right)-\left(X_{H L}-R_{H L}\right)\right]
\end{aligned}
$$

$\mathrm{IC}_{H H}$ and $\mathrm{IC}_{L H}$ of the ex-ante program ensure that $\mathrm{IC}_{H}$ is satisfied as long as:

$$
\gamma<(2 p-1)\left[\left(X_{L L}-R_{L L}\right)-\left(X_{H L}-R_{H L}\right)\right]
$$

The RHS of the expression above is positive because the principal moves the contract closer to the low-type agent's first best when a low signal is observed. The principal's utility from a lowtype agent when a low signal is observed $\left(X_{L L}-R_{L L}\right)$ is more than the principal's utility from a low-type agent when a high-signal is observed $\left(X_{H L}-R_{H L}\right)$. Thus, picking a gamma that is the minimum of $(2 p-1)\left[\left(X_{L L}-R_{L L}\right)-\left(X_{H L}-R_{H L}\right)\right]$ and the high-type agent's rent (the slack in $\mathrm{IR}_{H}$ ) will ensure that all constraints are satisfied and the expected payment to the high-type agent is reduced by a positive $\gamma$. The overall increase in the principal's expected utility $=\gamma * \operatorname{prob}\left[\theta=\theta_{L}\right]$

Proof of Proposition 4: Let $\hat{X}_{i j}, \hat{R}_{i j}$ be optimal in Program $_{E x-A n t e}$. It is obvious that $\hat{X}_{i j}$ and $\hat{R}_{i j}$ satisfy the IR and IC constraints of Program $E x-P o s t-3$. Constraint $\operatorname{ID}_{L}$ (for the lowtype agent) is also satisfied because in Program $_{E x-A n t e}$ both the LHS of $\operatorname{IR}_{L L}$ and the LHS of $\mathrm{IR}_{H L}$ are equal to zero. Let $U\left(\hat{R}_{L H}\right)-D\left(\hat{X}_{L H}, \theta_{H}\right)=K_{L}$ and $U\left(\hat{R}_{H H}\right)-D\left(\hat{X}_{H H}, \theta_{H}\right)=K_{H}$. We know from Lemma 2 that $K_{L}>K_{H}$. Let $R_{L H}=\hat{R}_{L H}-\alpha$ and $R_{H H}=\hat{R}_{H H}+\beta$ so that $U\left(R_{L H}\right)-D\left(\hat{X}_{L H}, \theta_{H}\right)=U\left(R_{H H}\right)-D\left(\hat{X}_{H H}, \theta_{H}\right)=K=(1-p) K_{L}+p K_{H} . \mathrm{IR}_{L}, \mathrm{IR}_{H}, \mathrm{IC}_{H}$, and

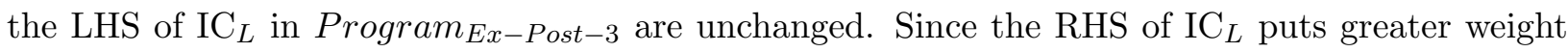
$(p)$ on the number that is being reduced $\left(R_{L H}\right)$, it is also reduced, so the $\mathrm{IC}_{L}$ is also met. Since the agent is risk-averse and $R_{L H}>R_{H H}$, the deviation suggested reduces the risk imposed on the agent and allows the principal to improve her utility. 


\section{Figure 1}

Contracting Sequence

$X_{S \theta}, R_{S \theta}$ : Output-compensation pair for signal S and agent-type $\theta$

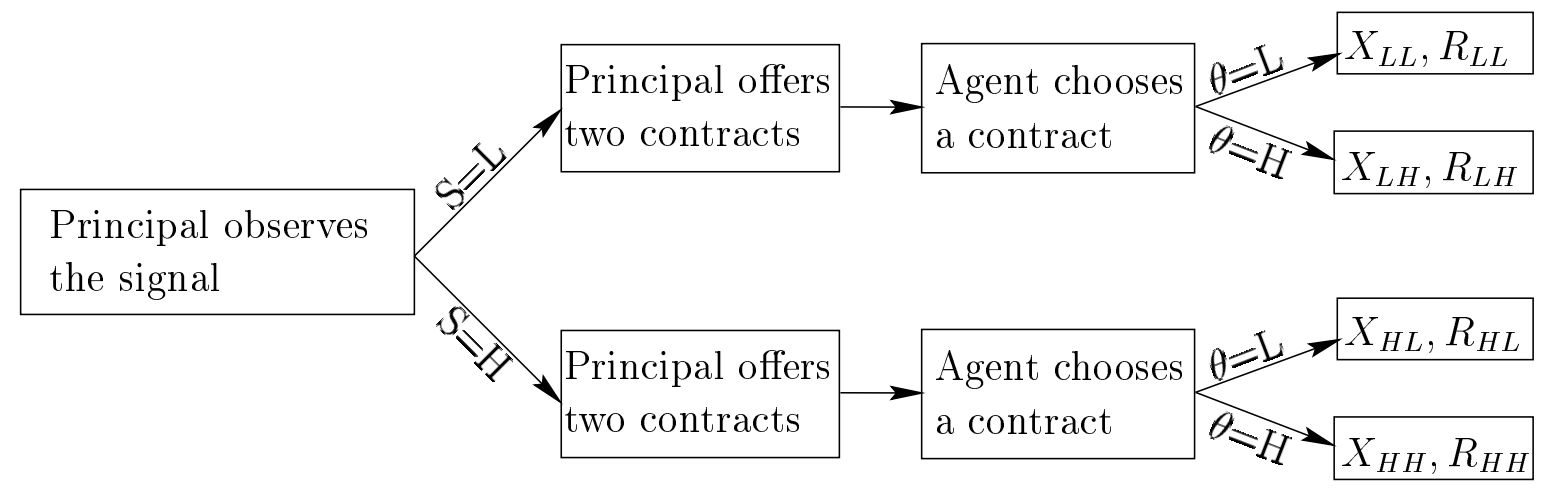

Figure 1(a): Ex-Ante Investigation

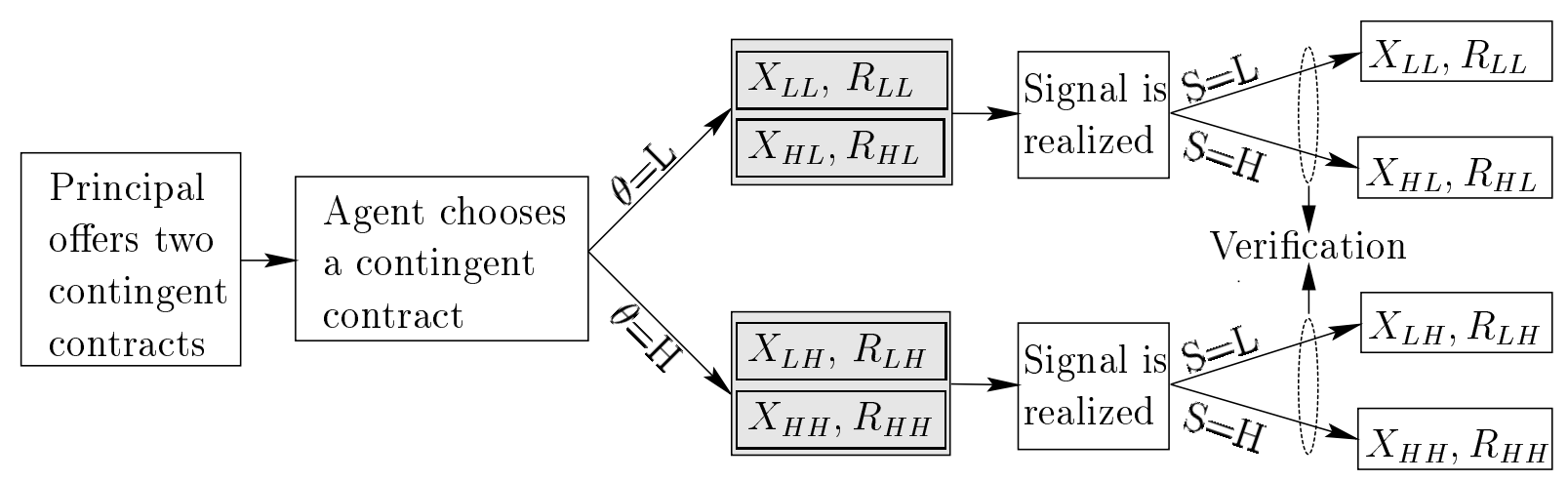

Figure 1(b): Ex-Post Investigation 


\section{Figure 2}

\section{Ex-Ante Investigation}

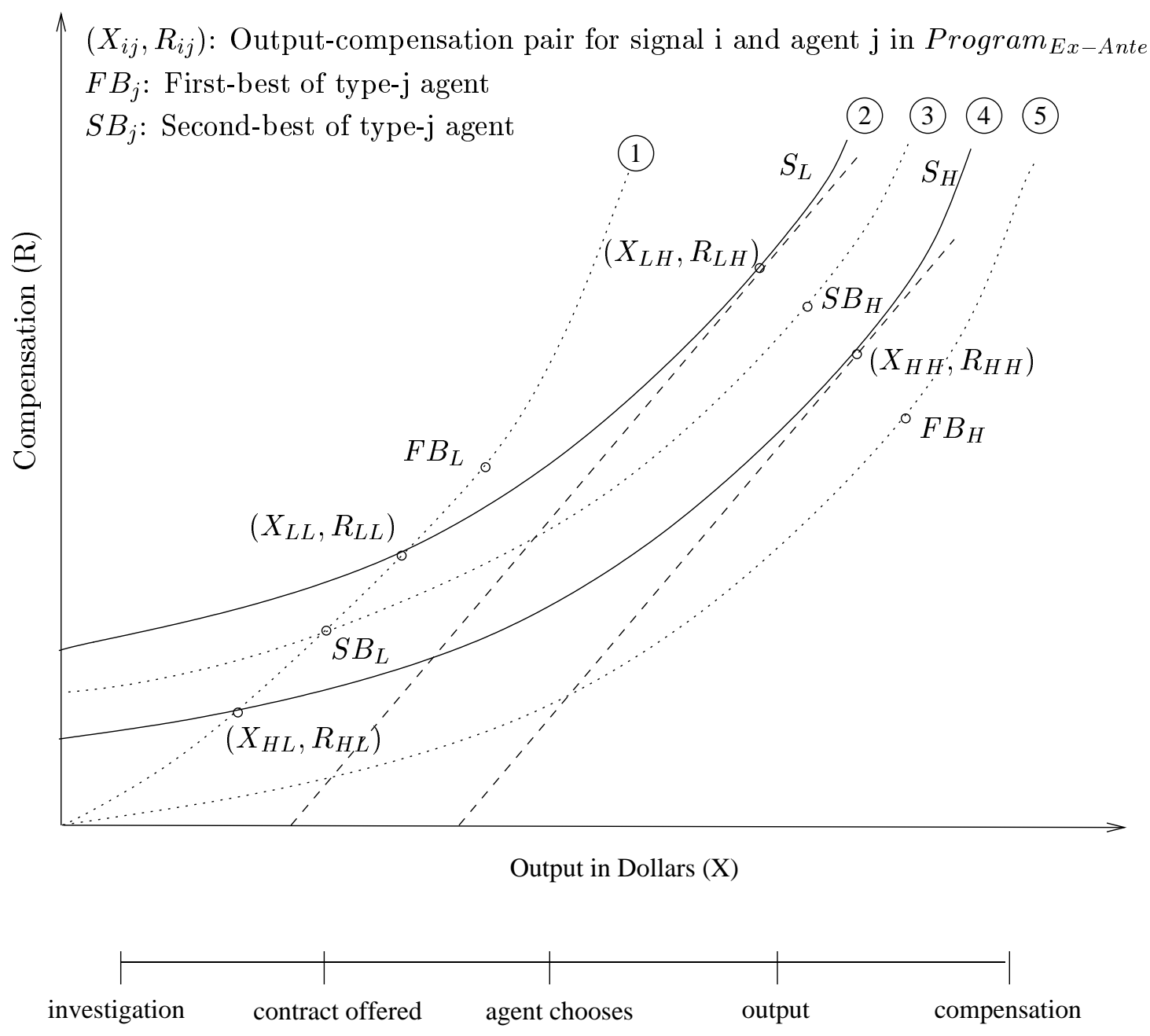

(1) Reservation utility indifference curve of the low-type agent.

(2) The high-type's indifference curve passing through the low-type's contract when the principal observes a low signal.

(3) The high-type's indifference curve passing through the low-type's SB contract.

(4) The high-type's indifference curve passing through the low-type's contract when the principal observes a high signal.

(5) Reservation utility indifference curve of the high-type. 


\section{Figure 3}

The Incentive Effect

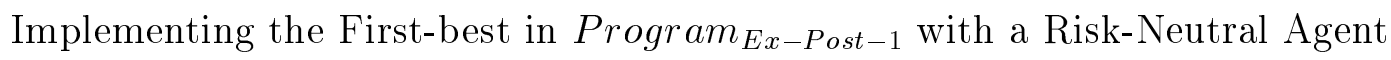

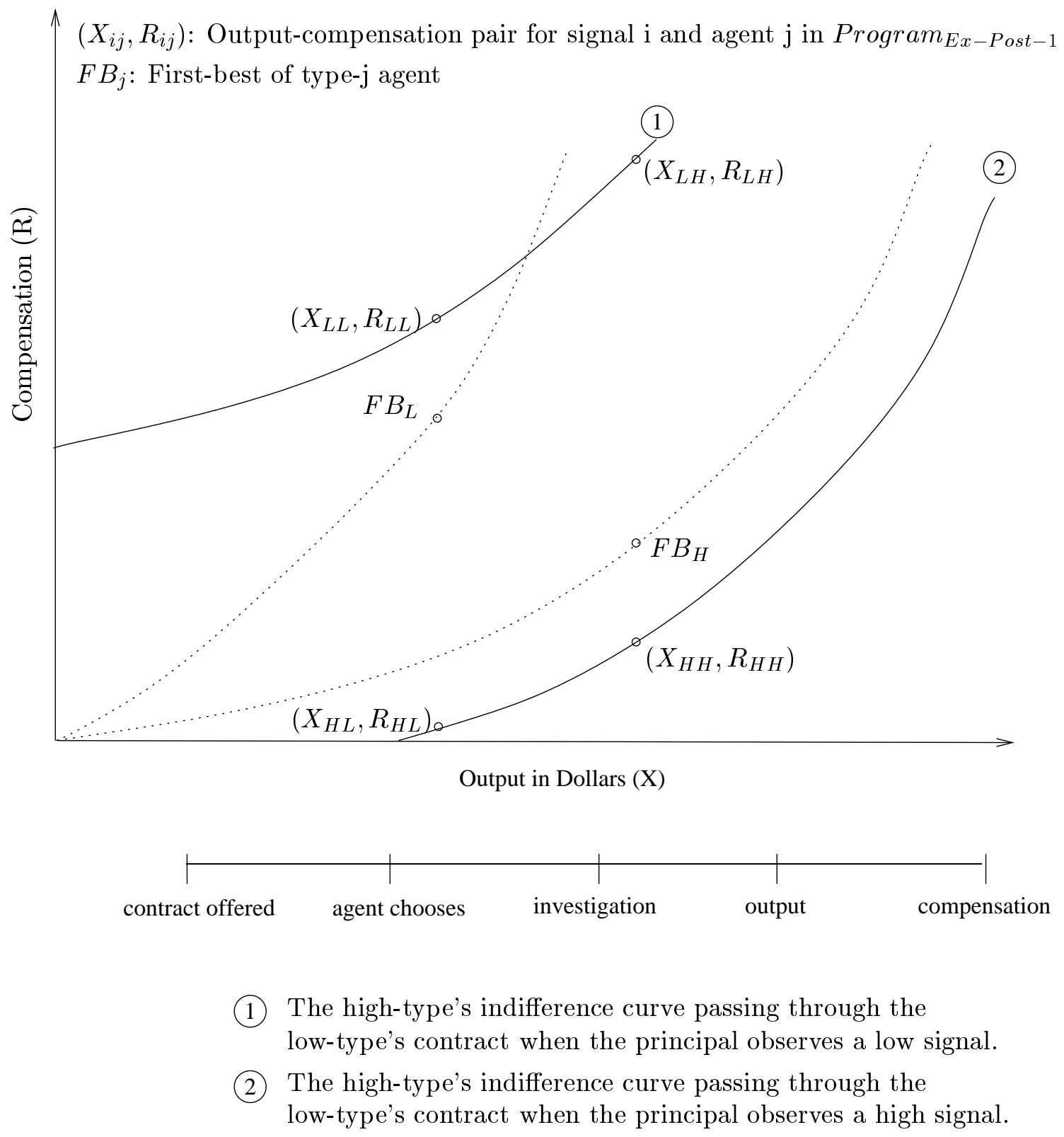




\section{Figure 4}

The Insurance Effect

Program $_{E x-\text { Post-1 }}$ Dominates Program $E x-$ Ante for a Risk-Averse Agent

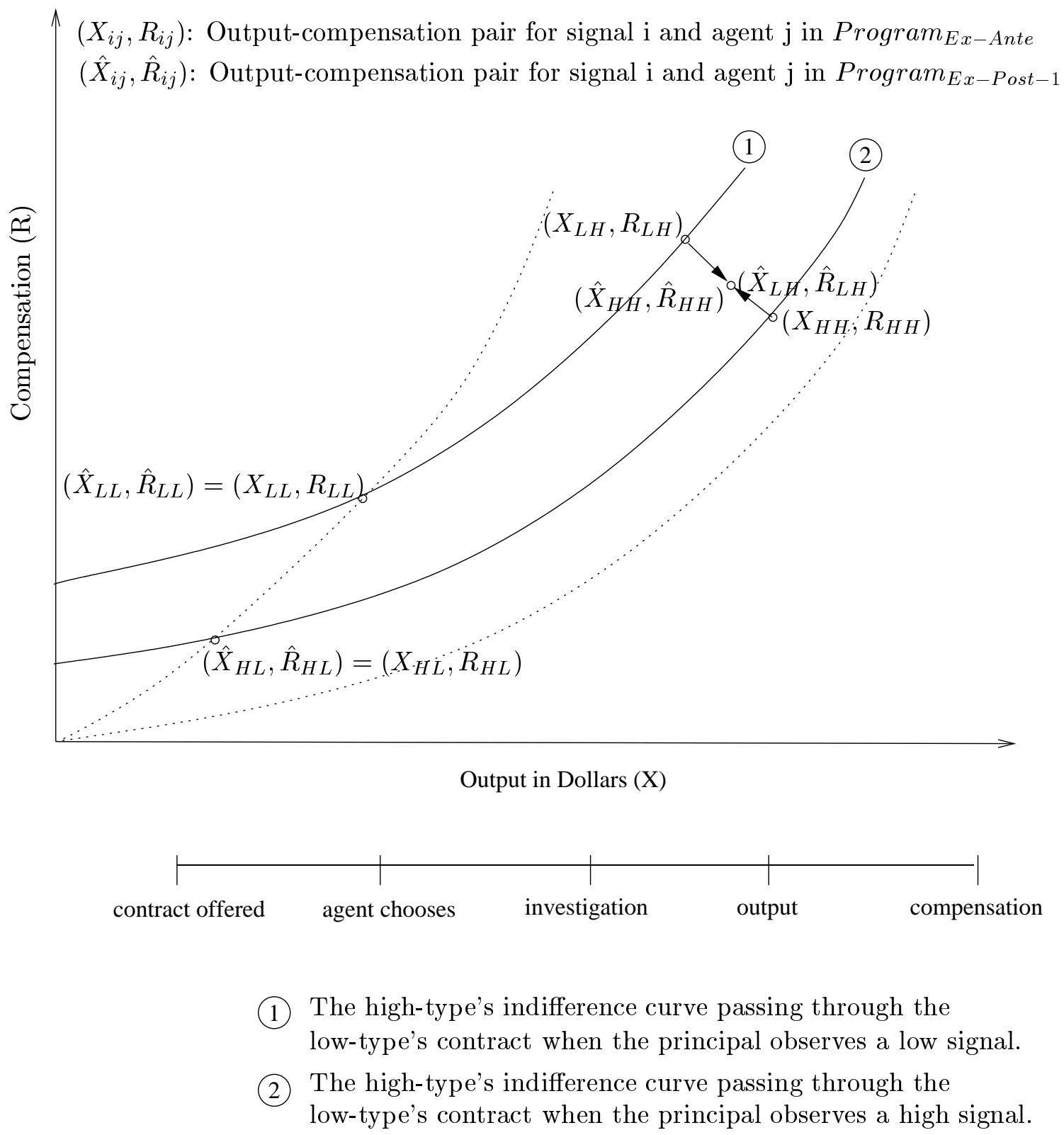




\section{Figure 5}

Program $_{E x-P o s t-2}$ Dominates Program ${ }_{E x-A n t e}$ for a Risk-Neutral Agent

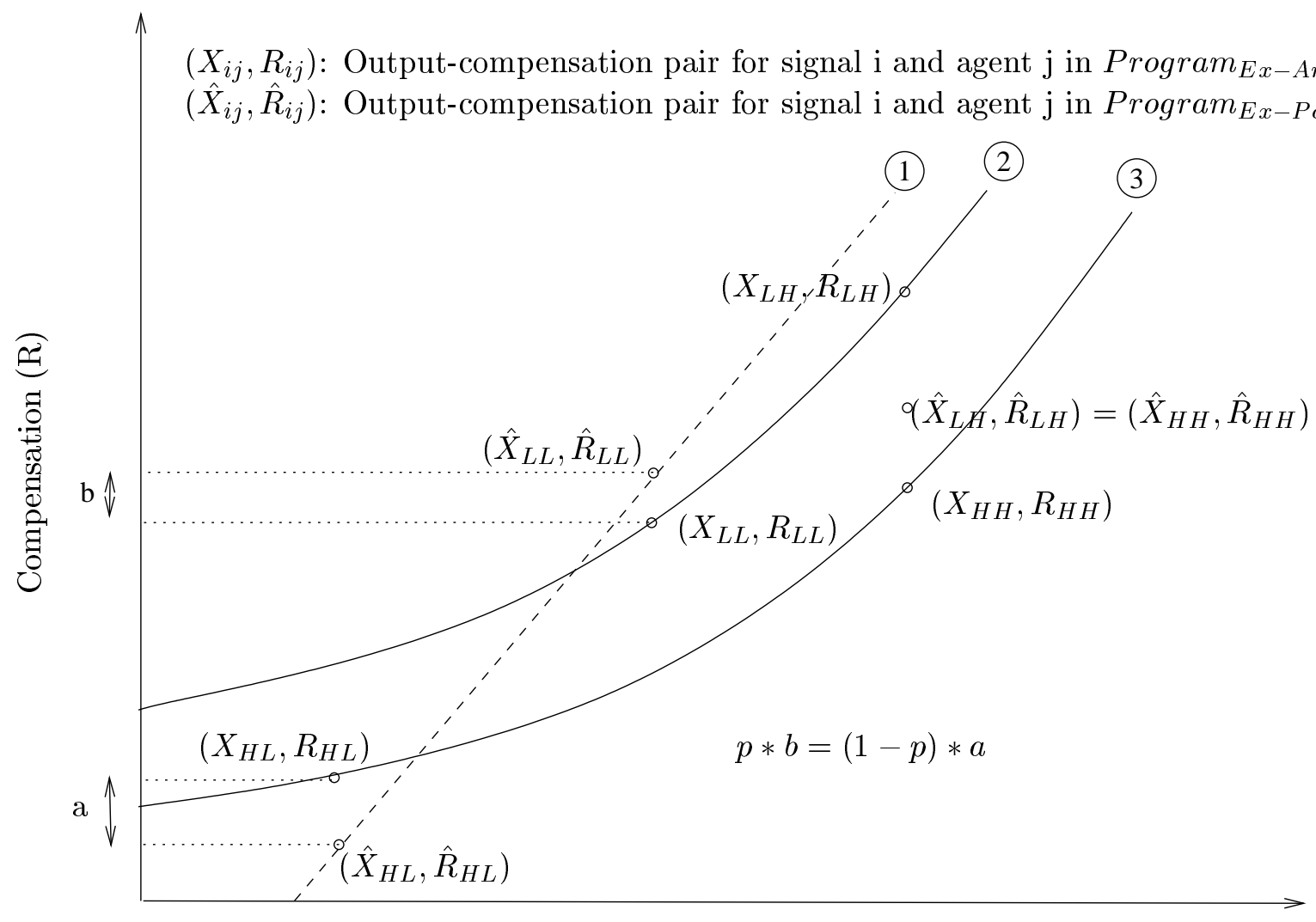

Output in Dollars (X)

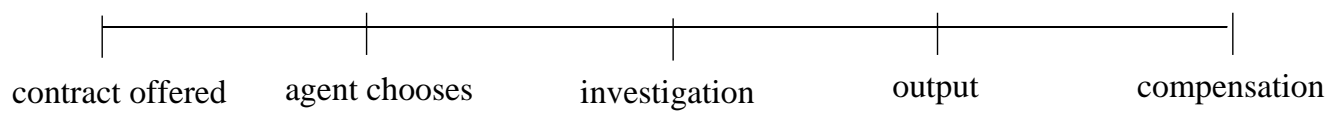

(1) The principal's indifference curve.

(2) The high-type's indifference curve passing through the low-type's contract when the principal observes a low signal.

(3) The high-type's indifference curve passing through the low-type's contract when the principal observes a high signal. 


\section{References}

Arya, A. and Glover, J. (1996). Verification of historical cost reports. Accounting Review, 71:2, $255-69$.

Baiman, S. and Evans, J. (1983). Pre-decision information and participative management control systems. Journal of Accounting Research, Autumn, 371-395.

Baiman, S. and Sivaramakrishnan, K. (1991). The value of private pre-decision information in a principal agent context. The Accounting Review, October, 747-767.

Baron, R. and Myerson, R. (1982). Regulating a monopolist with unknown costs. Econometrica, Vol. 50:4, 911-930.

Christensen, P. O. and Feltham, G. A. (1997). Sequential communication in agency. Review of Accounting Studies, 2:2, 123-155.

Cremer, J. and Khalil, F. (1992). Gathering information before signing a contract. American Economic Review, Vol. 82:3, 566-578.

Cremer, J. and McLean, R. (1988). Full extraction of the surplus in bayesian and dominant strategy auctions. Econometrica, Vol. 66, 1247-1257.

Demougin, D. M. and Garvie, D. A. (1991). Contractual design with correlated information under limited liability. Rand Journal of Economics, Vol. 22:4, Winter, 477-489.

Demski, J. S. and Feltham, G. A. (1978). Economics incentives in budgetary control systems. The Accounting Review, Vol. LIII, 336-359.

Demski, J. S. and Sappington, D. (1984). Optimal incentive contracts with multiple agents. Journal of Economic Theory, 33:1, 152-71.

Demski, J. S. and Sappington, D. (1991). Resolving double moral hazard problems with buyout agreements. Rand Journal of Economics, 22:2, 232-40.

Demski, J. S., Sappington, D., and Spiller, P. T. (1988). Incentive schemes with multiple agents and bankruptcy constraints. Journal of Economic Theory, 44:1, 156-67. 
Demski, J. S. and Sappington, D. E. M. (1993). Sourcing with unverifiable performance information. Journal of Accounting Research, v31:1, 1-20.

Dunne, S. A. and Loewenstein, M. A. (1995). Costly verification of cost performance and the competition for incentive contracts. Rand Journal of Economics, 26:4, 690-703.

Fellingham, J. and Young, R. (1990). The value of self-reported costs in repeated invest- ment decisions. The Accounting Review, October, 837-856.

Hermalin, B. E. and Katz, M. L. (1991). Moral hazard and verifiability: The effects of renegotiation in agency. Econometrica, 59:6, 1735-1753.

Kanodia, C. (1993). Participative budgets as coordination and motivational devices. Journal of Accounting Research, 31:2, 172-89.

Kerschbamer, R. (1994). Destroying the "Pretending" equilibria in the Demski-Sappington-Spiller model. Journal of Economic Theory, 62:1, 230-237.

Kirby, A., Reichelstein, S., Sen, P., and Paik, T. (1991). Partcipation, slack, and budget-based performance evaluation. Journal of Accounting Research, Vol. 29, 109-128.

Ledyard, J. (1986). The scope of the hypothesis of bayesian equilibrium. Journal of Economic Theory, 39, 59-82.

Melumad, N. D. and Reichelstein, S. (1987). Centralization versus delegation and the value of communication. Journal of Accounting Research, 25, 1-18.

Melumad, N. D. and Thoman, L. (1990). On auditors and the courts in an adverse selection setting. Journal of Accounting Research, Vol. 28, No. 1, Spring, 77-120.

Myerson, R. (1979). Incentive compatability and the bargaining problem. Econometrica, Vol. 47:1, $61-73$.

Myerson, R. (1983). Mechanism design by an informed principal. Econometrica, 51:6, 1767-97.

Rajan, M. V. (1992). Cost allocation in multiagent setting. The Accounting Review, Vol. 67:3, $527-545$.

Reichelstein, S. (1992). Constructing incentive schemes for government contracts: An application of agency theory. Accounting Review, 67:4, 712-31.

Robert, J. (1991). Continuity in auction design. Journal of Economic Theory, Vol. 55, 169-179. 